\title{
Palladium and Platinum Nanocatalysts Protected by Amphiphilic Block Copolymers
}

\author{
Andrea B. R. MAYER, James E. MARK, ${ }^{\dagger}$ and Randal E. MorRIs* \\ Department of Chemistry and the Polymer Research Center, \\ The University of Cincinnati, Cincinnati, Ohio 45221-0172, U.S.A. \\ * Department of Cell Biology, Neurobiology and Anatomy, \\ The University of Cincinnati, Cincinnati, Ohio 45267-0521, U.S.A.
}

(Received June 23, 1997)

\begin{abstract}
Several palladium and platinum colloids stabilized by polystrene- $b$-poly(methacrylic acid) (PS- $b$-PMAA) and polystyrene- $b$-poly(ethylene oxide) (PS- $b$-PEO) in a polar medium were prepared by in situ reductions from various precursors. Micelle formation of these diblock copolymers, as well as the particle sizes, morphologies, and size distributions of the metal nanoparticles were investigated by transmission electron microscopy. The catalytic activities of the colloidal metal nanoparticles were qualitatively determined by the hydrogenation of cyclohexane as a model reaction. The activities thus observed for these polymer-metal systems were found to depend significantly on precursor type and preparation conditions. These differences could be due to several factors, such as (i) partial embedding of the nanocatalysts within the hydrophobic micelle cores, (ii) influences of the side products of the reducing agent, or of the metal precursor counterions, or (iii) changes in the block copolymer micelle diameters or morphologies.
\end{abstract}

KEY WORDS Metal Nanoparticles / Colloids / Block Copolymers / Catalytic Hydrogenations /

Polymer-protected, nanosized transition metals are of great interest since they are very promising candidates for a wide variety of technological applications, such as catalysis. $^{1-28}$ The choice of the protective polymer is crucial for the stablization of the metal colloids and for the control of the particle sizes, size distributions and particle morphologies. In addition, the polymer influences the technological applicability and processability of these materials by providing certain solubilities, thermal stabilities and protective functions. In order to design metal-polymer systems for special needs, various types of protective polymers are worth investigating, since they can fulfill special functions in combination with the nanometal. In some of our previous research, various water-soluble homopolymers and random copolymers, as well as cationic polyelectrolytes have been studied for their abilities to stabilize noble metal colloids and their usefulness for catalytic applications. ${ }^{23-27}$ It was found that the catalytic activities of these materials, for instance, depend strongly on the type of protective polymer. ${ }^{23-26}$ Several other research groups have also investigated the utilization of polymer-protected metal colloids for selective catalytic reactions. ${ }^{1-8,21,22,28}$

One important group of polymers, which has lately received a lot of attention, are the amphiphilic block copolymers. Due to their ability to form micelles, for example, they can offer many advantages for the formation of colloidal systems. Not only are they very good steric stabilizers for metal colloids, ${ }^{29}$ but they can also be used to control their particle sizes and size distributions. This is based on the concept of the micelles acting as "molecular reactors" 7-15 for the formation of the nanoparticles. Such size-controlled metal or semiconductor nanoparticles have already been prepared by several groups for reverse-micelle systems. ${ }^{7-15}$ The incorporation of the nanoparticles into the hydrophilic micelle cores is achieved by the interaction of the precursors with the hydrophilic block, for instance, by complex or ion-pair formation. The incorporation of metal nanoparticles into hydrophobic micelle cores appears somewhat difficult, since usually there is a lack of strong interactions of most metal salt precursors with hydrophobic block components, such as polystyrene. Nevertheless, for some applications, the use of such systems in polar media could be desirable, and could have environmental advantages.

It can be expected that for most cases the introduction of metal salt precursors into block copolymer environments in polar media will result in the formation of the nanoparticles in the coronas of the micelles. These nanoparticles would be expected to be located in the vicinity to the hydrophobic micelle cores. The closeness would depend on the affinity of the metal nanoparticles to hydrophobic surfaces, and on the type of the hydrophilic block (providing more or less strong interactions with the precursors or nanoparticles). However, with careful selection of the precursor type (e.g., by varying its hydrophobicity and/or steric bulkiness), and of the reaction conditions (such as temperature and solvent selection) it should be possible to incorporate the nanoparticles into the hydrophobic micelle cores, at least to some extent. This, in turn, should have some effect on the catalytic properties, for instance, the catalytic activities of the systems. It should be possible to regulate this by selection of the polymer block types, the precursor type, and the reaction conditions. ${ }^{24}$ Another advantage offered by amphiphilic block copolymers is their ability to form various morphologies, and the morphological changes of several amphiphilic block copolymer systems were systematically studied by Eisenberg and coworkers. ${ }^{30-34}$ It was shown that these morphologies can be controlled by a variety of factors.

\footnotetext{
† To whom correspondence should be addressed (e-mail: jemark@ucbeh.san.uc.edu, URL: http://jemcom.crs.uc.edu/).
} 
This, in turn, could be highly useful for tuning the properties of such metal-block copolymer catalyst systems, especially if catalyst tuning during the course of a catalytic reaction is desired.

The by-products formed with the use of certain reducing agents, as well as the counterions stemming from the metal precursors, could have additional effects. An example would be promoting or inhibiting the catalytic properties of the systems, and this could be done systematically.

In the present investigation, several stable palladium and platinum colloids were prepared in the presence of two amphiphilic block copolymers, namely polystyene$b$-poly(methacrylic acid) (PS- $b$-PMAA) and polystyrene$b$-poly(ethylene oxide) (PS- $b$-PEO). Various metal precursors, reduction methods, and reduction conditions were employed, and the effects of these variations on the catalytic hydrogenation of cyclohexene were qualitatively investigated. Polar media based on ethanol were chosen. In this way, differences (e.g., in the hydrophobicities of the precursors) are better maintained than in, for instance, a purely aqueous medium. Furthermore, some variations with respect to solvent mixtures and thus the possibility of swelling the polystyrene core or changing the copolymer morphology were possible. The particle sizes, morphologies, size distributions, and the locations of the metal nanoparticles (i.e., vicinity and/or partial embedding in the micelle core, or in the corona) were investigated by transmission electron microscopy (TEM). The catalytic activity was found to depend on the precursor type, the reducing agent, and the preparation conditions. These differences might be attributed to several factors that could influence catalyst activity, namely (i) partial embedding of the palladium nanocatalysts within the hydrophobic micelle cores, (ii) influences of the by-products of the reducing agents, or of the metal precursor counterions, or (iii) changes in the diameters or morphologies of the block copolymer (or "substrate") micelles.

\section{EXPERIMENTAL}

\section{Chemicals and Reagents}

The metal precursors palladium chloride $\left(\mathrm{PdCl}_{2}\right)$, palladium acetate $\left[\mathrm{Pd}\left(\mathrm{CH}_{3} \mathrm{COO}\right)_{2} ; \mathrm{Pd}(\mathrm{ac})_{2}\right]$, palladium trifluoroacetate $\left[\mathrm{Pd}\left(\mathrm{CF}_{3} \mathrm{COO}\right)_{2} ; \mathrm{Pd}\left(\mathrm{F}_{3} \mathrm{ac}\right)_{2}\right]$, palladium acetylacetonate $\quad \mathrm{Pd}\left[\mathrm{CH}_{3} \mathrm{COCH}=\mathrm{C}(\mathrm{O}-) \mathrm{CH}_{3}\right]_{2}$; $\left.\mathrm{Pd}(\mathrm{acac})_{2}\right\}$, dihydrogen hexachloroplatinate hydrate $\left(\mathrm{H}_{2} \mathrm{PtCl}_{6} \cdot \mathrm{H}_{2} \mathrm{O}\right)$, and platinum(II)acetylacetonate $\{\mathrm{Pt}-$ $\left.\left[\mathrm{CH}_{3} \mathrm{COCH}=\mathrm{C}\left(\mathrm{O}_{-}\right) \mathrm{CH}_{3}\right]_{2} ; \mathrm{Pt}(\mathrm{acac})_{2}\right\}$ were obtained from Aldrich. The block copolymers were purchased from Polymer Source, and had the following molecular weights: PS- $b$-PMAA (number-average molecular weight $M_{n}$ of PS 6,$500 ; M_{n}$ of PMAA 16,000 ; polydispersity index $\left.M_{w} / M_{n}=1.02\right)$, and PS- $b$-PEO $\left(M_{n}\right.$ of PS 29,800 ; $M_{n}$ of PEO 8,$\left.400 ; M_{w} / M_{n}=1.03\right)$. The reducing agents potassium borohydride $\left(\mathrm{KBH}_{4}\right)$ and sodium hypophosphite monohydrate $\left(\mathrm{NaH}_{2} \mathrm{PO}_{2} \cdot \mathrm{H}_{2} \mathrm{O}\right)$ were purchased from Aldrich.

\section{Colloid Preparation}

a) Reductions by Refluxing the Solutions. The metal colloids were prepared using a method described by Hirai et $a l .^{3}$ The metal precursors were reduced by refluxing the solutions $\left(6.8 \times 10^{-4} \mathrm{M}\right)$ containing the block copolymers in a mass ratio of copolymer: palladium $=$ $25: 1$. The oil-bath temperature was kept at about $100^{\circ} \mathrm{C}$. For PS- $b$-PMAA ethanol (EtOH) was used as a solvent, for PS- $b$-PEO solvent mixtures of tetrahydrofuran (THF) and $\mathrm{EtOH}$ were used. For the preparation of the PS- $b$-PEO samples the block copolymer was first dissolved in the desired amount of THF, and EtOH was then added dropwise, resulting in initial solvent mixtures of THF : EtOH $=1: 9(\mathrm{v} / \mathrm{v})$ or $16: 9(\mathrm{v} / \mathrm{v})$. The metal precursors were slowly added as solutions in EtOH (equal volumes of block copolymer and metal precursor solution were combined), thus resulting in final solvent mixtures of $\mathrm{THF}: \mathrm{EtOH}=1: 19(\mathrm{v} / \mathrm{v})$ or $1: 2.1(\mathrm{v} / \mathrm{v})$.

b) Reductions by Heating below Reflux Temperatures. For the $\mathrm{Pd}(\mathrm{ac})_{2}$ and $\mathrm{Pd}\left(\mathrm{F}_{3} \mathrm{Ac}\right)_{2}$ precursors some reductions were performed in a sandbath at $60^{\circ} \mathrm{C}$. The other reduction conditions were the same as those described in part a).

c) Reductions at Room Tempeature. Some palladium colloids were prepared from the $\operatorname{Pd}(\mathrm{ac})_{2}$ and $\operatorname{Pd}\left(\mathrm{F}_{3} \mathrm{ac}\right)_{2}$ precursors by stirring the solutions at room temperature. The concentrations, mass ratio, and solvents were the same as those described in part a).

d) Reductions by Potassium Borohydride. An aqueous solution of $\mathrm{KBH}_{4}\left(0.0015 \mathrm{~g} \mathrm{KBH}_{4}\right.$ in $0.2 \mathrm{ml}$ distilled water) was prepared just before use and $0.05 \mathrm{ml}$ was rapidly added to $0.8 \mathrm{ml}$ of the stirred solutions $\left(6.8 \times 10^{-4} \mathrm{M}\right.$, room tempeature $)$ which contained the metal precursors and the block copolymers. The mass ratio and the solvents used were the same as described in a). Potassium borohydride was used instead of the more commonly employed sodium borohydride. In this way it was possible to prepare an aqueous solution immediately before the addition to the reaction mixtures, due to its slightly lower reactivity with water. Also, a more exact measurement of the borohydride added was possible, especially with the small quantities used for these experiments. The addition as a solution furthermore allows better and immediate mixing of the reactants.

e) Reductions by Sodium Hypophosphite. An aqueous solution of $\mathrm{NaH}_{2} \mathrm{PO}_{2} \cdot \mathrm{H}_{2} \mathrm{O}\left(0.0015 \mathrm{~g} \quad \mathrm{NaH}_{2} \mathrm{PO}_{2}\right.$ in $0.2 \mathrm{ml}$ distilled water) was freshly prepared and $0.05 \mathrm{ml}$ was rapidly added to $0.8 \mathrm{ml}$ of the reaction mixtures stirred at room tempeature. The precursor concentration, mass ratio, and solvent mixtures were the same as those described under part a).

All glassware was cleaned with aqua regia (for the platinum samples) or concentrated nitric acid (for the palladium samples) before use. Especially for the palladium acetate and palladium trifluoroacetate samples, freshly prepared precursor solutions were used because of the easy reduction of these precursors in ethanol, even at room temperature.

\section{Characterization}

A JEOL-100 XC II electron microscope (operated at $80 \mathrm{kV}$ ) was used to obtain the sizes, morphologies, and size distributions of the metal nanoparticles. The samples were prepared by placing a drop of the colloidal dispersion on a formvar/carbon-coated copper grid and 
letting the solvent evaporate. The metal particle sizes were measured with a comparator and the average particle sizes and size distributions were determined based on the measurement of at least 150 particles. The sizes of the micelles were estimated from the TEM micrographs as well. The relative changes in micelle size and morphology due to changes in solvent composition, quality, and polarity can be explained to mainly stem from changes of the micelle core (i.e., expansions, due to good solvent for the core component, THF, having been added in various amounts). No special shadowing technique was used for the TEM micrographs. The patterning and arrangement of the shadowed regions on the TEM micrographs, however, suggest that the micelle cores are indeed being seen. Also, the arrangement of the metal nanoparticles for many samples are expected to be located close to the micelle cores, therefore "describing" their dimensions. However, for the interpretation of the presented results the only relevant quantities are the relative and not the absolute changes of the micelle size (i.e., relative changes of the sizes of the micelle cores and thus their changes in "density"). In the text and tables, however, references to micelle dimensions should be understood to be estimates and relative, comparative values, used primarily to characterize changes of the micelle core dimensions.

\section{Catalytic Hydrogenations}

The hydrogenations were carried out with a Parr hydrogenation apparatus (shaker type) at room temperature. For the qualitative comparison of the catalytic activities, cyclohexene $(0.05 \mathrm{ml})$ was added to $10 \mathrm{ml}$ methanol, and the metal catalysts were added as colloidal dispersions. An amount of catalyst that corresponds to $0.09 \mathrm{wt} \%$ palladium and $0.16 \mathrm{wt} \%$ platinum (with respect to cyclohexene) was added. The amounts were calculated taking into account the addition of water for the reductions described in parts d) and e), and associated changes in colloid concentration. The catalytic reactions were carried out for $30 \mathrm{~min}$ at a hydrogen pressure of $10 \mathrm{psi}$. Test reactions without the addition of any catalyst were performed in between each reaction. The reaction mixtures were analyzed by gas chromatography (SE-30 packed column) with a flame ionization detector, and helium as the carrier gas.

\section{RESULTS AND DISCUSSION}

Table I summarizes the results for palladium nanoparticles protected by the PS- $b$-PMAA diblock copolymer. The respective palladium precursors, reduction methods, average particle diameters, and micelle sizes/ block copolymer morphologies are listed, along with the catalytic activities in terms of percent conversion of cyclohexene.

There does not seem to be a pronounced dependence of the catalytic activities on the particle sizes. However, several other factors can be taken into consideration for explaining the activities found. Ethanol was the solvent for these systems, and in most cases the diameters of the micelles, as estimated from the TEM micrographs, were about $15 \mathrm{~nm}$. In three cases, namely the $\mathrm{KBH}_{4}$ reductions for the $\mathrm{PdCl}_{2}$ and $\mathrm{Pd}(\mathrm{acac})_{2}$ precursors, the TEM
Table I. Palladium nanocatalysts protected by PS- $b$-PMAA

\begin{tabular}{|c|c|c|c|c|}
\hline Precursor & $\begin{array}{l}\text { Reduction } \\
\text { method }\end{array}$ & $\begin{array}{l}\text { Catalytic } \\
\text { activity } \\
\% \text { cyclo- }^{-} \\
\text {hexane }^{\mathrm{a}}\end{array}$ & $\begin{array}{c}\text { Average } \\
\text { particle } \\
\text { diameter/nm } \\
\text { (std. dev.) }\end{array}$ & $\frac{\begin{array}{c}\text { Micelle } \\
\text { diameter }^{\mathrm{b}}\end{array}}{\mathrm{nm}}$ \\
\hline $\mathrm{PdCl}_{2}$ & Refluxing & 23.1 & $7.9(6.3)$ & $\sim 15$ \\
\hline $\mathrm{PdCl}_{2}$ & $\mathrm{KBH}_{4}$ & 33.5 & $2.1(1.2)$ & -c $^{\mathrm{c}}$ \\
\hline $\operatorname{Pd}(\mathrm{ac})_{2}$ & Refluxing & 13.8 & $3.4(0.8)$ & $\sim 15$ \\
\hline $\operatorname{Pd}(\mathrm{ac})_{2}$ & $\mathrm{KBH}_{4}$ & 14.6 & $1.3(0.5)$ & $\sim 15$ \\
\hline $\mathrm{Pd}(\mathrm{ac})_{2}$ & Room temperature & 6.1 & $1.0(0.9)$ & $\sim 15$ \\
\hline $\mathrm{Pd}(\mathrm{ac})_{2}$ & $60^{\circ} \mathrm{C}$ & 8.2 & $1.3(1.2)$ & $\sim 15$ \\
\hline $\operatorname{Pd}(\mathrm{ac})_{2}$ & $\mathrm{NaH}_{2} \mathrm{PO}_{2}$ & 52.3 & $2.5(1.6)$ & $\sim 15$ \\
\hline $\mathrm{Pd}\left(\mathrm{F}_{3} \mathrm{ac}\right)_{2}$ & Room temperature & 6.2 & $3.5(1.5)$ & $\sim 15$ \\
\hline $\operatorname{Pd}\left(\mathrm{F}_{3} \mathrm{ac}\right)_{2}$ & $60^{\circ} \mathrm{C}$ & 8.3 & $2.7(1.0)$ & $\sim 15$ \\
\hline $\mathrm{Pd}\left(\mathrm{F}_{3} \mathrm{ac}\right)_{2}$ & $\mathrm{NaH}_{2} \mathrm{PO}_{2}$ & $34.2^{\mathrm{d}}$ & $1.8(0.4)$ & $\sim 15-22$ \\
\hline $\mathrm{Pd}(\mathrm{acac})_{2}$ & Refluxing & 11.8 & $6.3(3.8)$ & $\sim 14-20$ \\
\hline $\operatorname{Pd}(\mathrm{acac})_{2}$ & Stirred/Refluxing ${ }^{\mathrm{e}}$ & 15.8 & $5.4(2.6)$ & $\sim 15$ \\
\hline $\mathrm{Pd}(\mathrm{acac})_{2}$ & $\mathrm{KBH}_{4}$ & 80.7 & $2.0(0.7)$ & $\sim 15$, loose \\
\hline $\operatorname{Pd}(\mathrm{acac})_{2}$ & Stirred/ $/ \mathrm{KBH}_{4}{ }^{\mathrm{e}}$ & 54.6 & $2.1(0.9)$ & $\sim 35$ \\
\hline
\end{tabular}

${ }^{a}$ Hydrogenation conditions: $0.05 \mathrm{ml}$ cyclohexene, $0.09 \mathrm{wt} \%$ palladium, $10 \mathrm{ml}$ methanol, hydrogen pressure $10 \mathrm{psi}$, hydrogenation time 30 min. ${ }^{b}$ Estimated from TEM micrographs. ${ }^{c}$ Not seen on TEM micrographs. ${ }^{\mathrm{d}}$ Hydrogenation conditions (due to smaller amount of colloid available), same as in footnote a, but with one third of the amounts. 'Stirring time, two days.

micrographs indicated that there were either no defined micelles (for the $\mathrm{PdCl}_{2}$ precursor), or there were only "loose" aggregates or enlarged micelles (for the $\mathrm{Pd}(\mathrm{acac})_{2}$ precursor). Figures 1 and 2 show some of these TEM micrographs, for palladium nanoparticles reduced from the $\mathrm{Pd}(\mathrm{acac})_{2}$ precursor by $\mathrm{KBH}_{4}$ (both with and without previous stirring) in the presence of PS- $b$-PMAA. This change in morphology most likely stems from the combined influence of the various ions present (stemming from the reducing agent and the precursor counterions), and from the change of the solvent polarity (due to the addition of the reducing agent as an aqueous solution). The finding that larger "loose" micelles are present despite the higher solvent polarity is surprising at first. However, the presence of ions that can influence the poly(methacrylic acid) corona should have a considerable influence, ${ }^{30-34}$ especially since an excess of reducing agent was used. Possibly a transition to a different morphology is taking place.

It is interesting to note that in these cases the catalytic activities are increased in comparison to the samples being reduced by refluxing from the same precursors, with the presence of defined spherical micelles. It can be assumed that with the higher temperature employed during the reduction by refluxing, the hydrophobic micelle cores allow partial embedding of the nanoparticles, and thus shield the catalytically active and available sites to a certain extent. Blocking of catalytically active sites by strong hydrophobic interactions and sorption between the metal surface and the hydrophobic block is responsible for the reduced catalytic activities. Therefore, the position of the catalyst nanoparticles with respect to the hydrophobic micelle core should have an influence on the catalytic activity, i.e., the more embedded the particle, or the closer its location towards the micelle core, the lower should be its activity. For the "loose" aggregates, however, it can be expected that the 


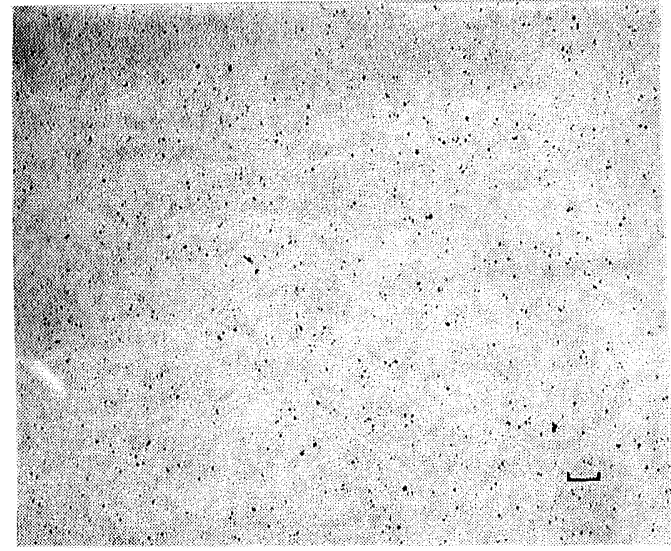

Figure 1. Palladium nanoparticles reduced by $\mathrm{KBH}_{4}$, from $\mathrm{Pd}(\mathrm{acac})_{2}$ in the presence of PS- $b$-PMAA (bar $=42 \mathrm{~nm}$ ).

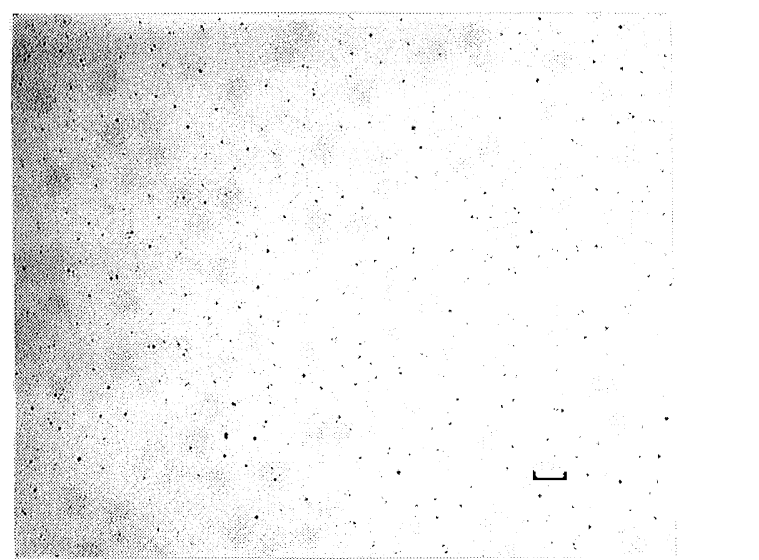

Figure 2. Palladium nanoparticles reduced by $\mathrm{KBH}_{4}$, with previous stirring for two days, from $\mathrm{Pd}(\mathrm{acac})_{2}$ in the presence of PS- $b$-PMAA (bar $=42 \mathrm{~nm}$ )

palladium nanoparticles are less-densely surrounded by the hydrophobic polystyrene blocks, or that they are only located in the corona. A good solvent system for the hydrophilic block component was used, which should give more flexibility and less-dense attachments around the palladium nanoparticles. This should result in an easier availability of the active sites for the catalytic reaction to occur, which expresses itself in the increased catalytic activity observed.

The values for the catalytic conversion of cyclohexene for the $\mathrm{Pd}(\mathrm{ac})_{2}$ precursor are comparable to one another for both reduction methods (namely the reduction by refluxing the ethanolic solution and the borohydride reduction). In both cases, micelles with a diameter of about $15 \mathrm{~nm}$ can be seen on the TEM micrographs, as shown in Figures 3 and 4 . (The micelles appear less well defined for the sample reduced by $\mathrm{KBH}_{4}$ than for the sample reduced by refluxing). These catalytic activities are also comparable to the values obtained for the $\mathrm{Pd}(\mathrm{acac})_{2}$ precursor in combination with the reduction by refluxing the ethanolic solutions. This is not so, however, for $\mathrm{PdCl}_{2}$ as a precursor prepared by the same reduction method (for which the catalytic activity is higher in comparison). This difference could stem from the varying degrees of hydrophobicity of the precursors and thus a different degree of incorporation and embedding into the micelle cores. The $\mathrm{Pd}(\mathrm{ac})_{2}, \mathrm{Pd}(\mathrm{acac})_{2}$

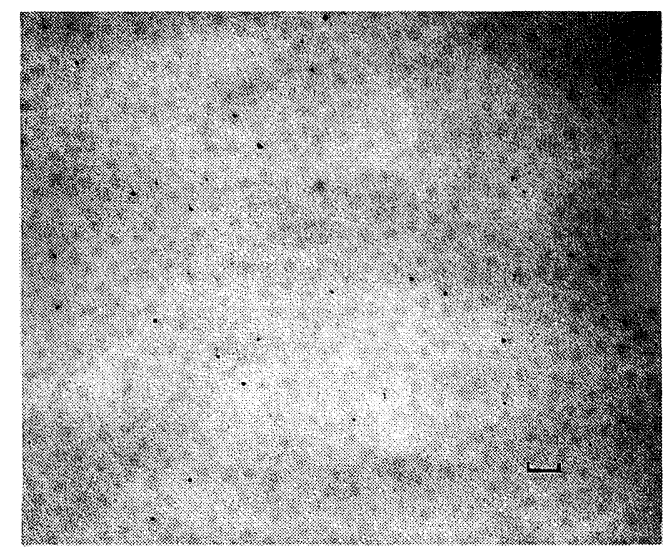

Figure 3. Palladium nanoparticles reduced by refluxing the ethanolic solution, from $\mathrm{Pd}(\mathrm{ac})_{2}$ precursor in the presence of PS- $b$-PMAA $($ bar $=42 \mathrm{~nm})$.

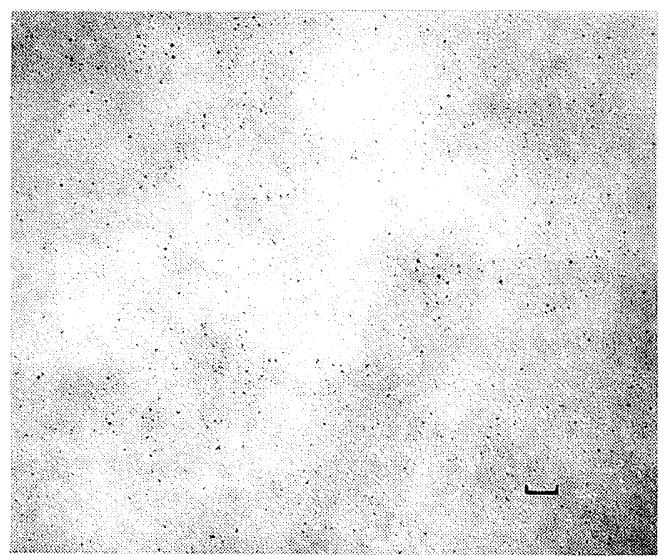

Figure 4. Palladium nanoparticles reduced by $\mathrm{KBH}_{4}$ from $\mathrm{Pd}(\mathrm{ac})_{2}$ precursor in the presence of PS- $b$-PMAA $($ bar $=30 \mathrm{~nm})$.

presursors are more hydrophobic than $\mathrm{PdCl}_{2}$ in the present solvent system, and therefore could possess a somewhat higher affinity towards the hydrophobic micelle core.

This effect could possibly also be responsible for the decreased catalytic activity for the $\mathrm{Pd}(\mathrm{acac})_{2}$ precursor, reduced by $\mathrm{KBH}_{4}$ but stirred for two days prior to the reduction. Here, due to the stirring time the precursor could be accumulated to a somewhat higher extent towards the micelle core or be partially incorporated at its periphery, therefore resulting in reduced catalytic activity of the palladium particles after reduction. It has to be pointed out that no complete incorporation of the precursor or the resulting metal nanoparticle into the hydrophobic micelle core is expected. However, certain differences in the precursor type and reduction conditions could influence the accumulation towards the core, and partial incorporation/embedding on the periphery of the micelle core seems likely. Due to the larger steric hindrance of the $\operatorname{Pd}(\mathrm{acac})_{2}$ precursor in comparison to, for instance, $\operatorname{Pd}(\mathrm{ac})_{2}$ the stirring time might make a major difference, especially for the roomtemperature reduction. Thus, steric effects of the precursors in combination with their hydrophobicity have to be considered as well. $\operatorname{Pd}(\mathrm{acac})_{2}$ as the sterically most-hindered precursor should be more difficult to be partially incorporated into the micelle core, especially at 


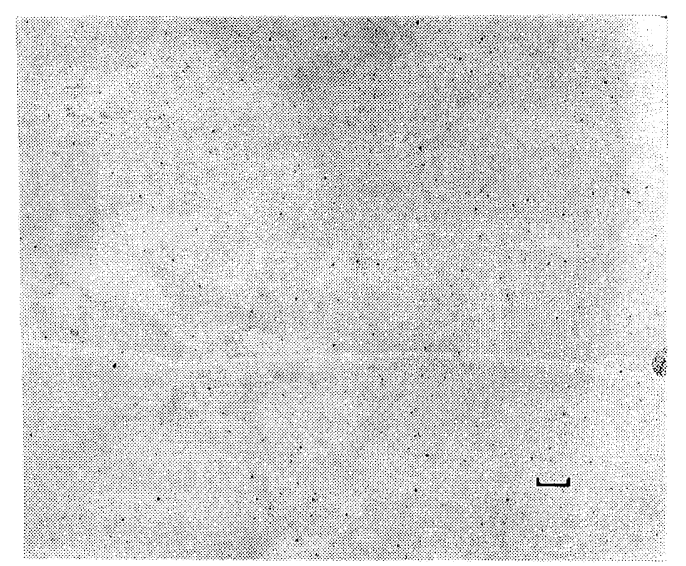

Figure 5. Palladium nanoparticles reduced by stirring the ethanolic solution at $60^{\circ} \mathrm{C}$, from $\mathrm{Pd}\left(\mathrm{F}_{3} \mathrm{ac}\right)_{2}$ precursor in the presence of PS- $b$ PMAA $($ bar $=62 \mathrm{~nm})$

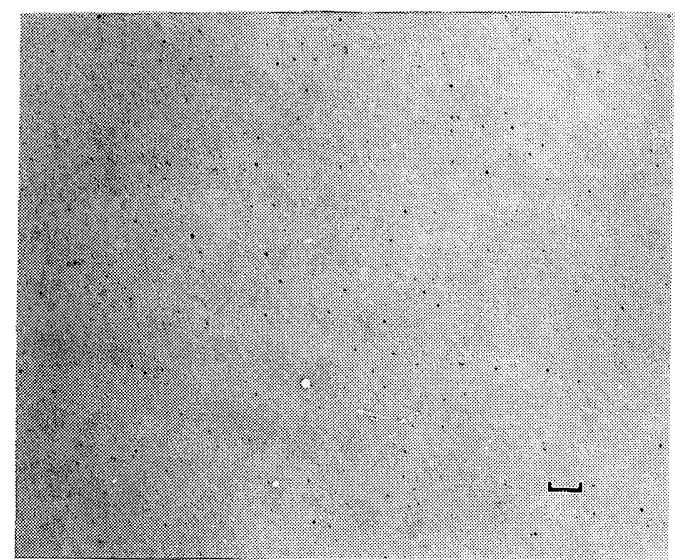

Figure 6. Palladium nanoparticles reduced by stirring the ethanolic solution at $60^{\circ} \mathrm{C}$, from $\mathrm{Pd}(\mathrm{ac})_{2}$ precursor in the presence of PS- $b$ PMAA $($ bar $=53 \mathrm{~nm})$.

lower temperatures. These considerations seem to be confirmed by the higher catalytic activities observed for the $\mathrm{KBH}_{4}$ reductions. With the borohydride reduction performed about five minutes after mixing the block copolymer and the $\operatorname{Pd}(\mathrm{acac})_{2}$ solutions, the precursor is reduced "outside" the micelle cores. This should in return result in less-embedded particles and higher catalytic activities. This difference should be less pronounced for higher temperatures during the preparation of the colloids, and this is confirmed by the catalytic data obtained.

Another interesting feature is observed for the $\mathrm{Pd}(\mathrm{ac})_{2}$ and $\operatorname{Pd}\left(\mathrm{F}_{3} \mathrm{ac}\right)_{2}$ precursors. These precursors are easily reduced even at room temperature by stirring of the ethanolic solutions. The values obtained for the catalytic activities of the samples prepared by the mere stirring at room temperature, and by stirring at $60^{\circ} \mathrm{C}$ are very similar for the respective precursors, demonstrating the reliability of the values obtained. Figure 5 shows the TEM micrograph of palladium nanoparticles reduced by stirring at $60^{\circ} \mathrm{C}$ from $\mathrm{Pd}\left(\mathrm{F}_{3} \mathrm{ac}\right)_{2}$ in the presence of PS- $b$-PMAA, and Figure 6 the corresponding sample prepared from $\mathrm{Pd}(\mathrm{ac})_{2}$. The TEM micrographs look very similar for both samples, which is consistent with the similar catalytic activities observed.

Thus, several factors might be important for the par-
Table II. Palladium nanocatalysts protected by PS- $b$-PEO

\begin{tabular}{|c|c|c|c|c|}
\hline Precursor & $\begin{array}{l}\text { Reduction } \\
\text { method }\end{array}$ & $\begin{array}{c}\text { Catalytic } \\
\text { activity } \\
\% \text { cyclo- } \\
\text { hexane }^{\mathrm{a}}\end{array}$ & $\begin{array}{c}\text { Average } \\
\text { particle } \\
\text { diameter/nm } \\
\text { (std. dev.) }\end{array}$ & $\frac{\begin{array}{c}\text { Micelle } \\
\text { diameter }^{\mathrm{b}}\end{array}}{\mathrm{nm}}$ \\
\hline $\mathrm{PdCl}_{2}$ & $\begin{array}{l}\text { Refluxing } \\
\text { THF }: \text { EtOH }=1: 2.1\end{array}$ & 24.9 & $6.6(2.0)$ & $\sim 22$ \\
\hline $\mathrm{PdCl}_{2}$ & $\begin{array}{l}\mathrm{KBH}_{4} \\
\mathrm{THF}: \mathrm{EtOH}=1: 2.1\end{array}$ & 21.5 & $3.4(1.3)$ & $\sim 38$ \\
\hline $\mathrm{PdCl}_{2}$ & $\begin{array}{l}\mathrm{KBH}_{4} \\
\text { THF }: \text { EtOH }=1: 19\end{array}$ & 40.6 & $3.6(1.3)$ & $\sim 18$, strings \\
\hline $\operatorname{Pd}(\mathrm{ac})_{2}$ & $\begin{array}{l}\text { Refluxing } \\
\text { THF }: \text { EtOH }=1: 2.1\end{array}$ & 21.4 & $4.3(1.1)$ & $\sim 22$ \\
\hline $\operatorname{Pd}(\mathrm{ac})_{2}$ & $\begin{array}{l}\text { Room temperature } \\
\text { THF }: \text { EtOH }=1: 2.1\end{array}$ & 18.4 & $2.1(1.4)$ & $\sim 22$ \\
\hline $\operatorname{Pd}(\mathrm{ac})_{2}$ & $\begin{array}{l}\text { Room temperature } \\
\text { THF : EtOH }=1: 19\end{array}$ & 28.1 & $2.7(0.7)$ & $\sim 18$ \\
\hline $\operatorname{Pd}(\mathrm{ac})_{2}$ & $\begin{array}{l}60^{\circ} \mathrm{C} \\
\mathrm{THF}: \mathrm{EtOH}=1: 19\end{array}$ & $15.8^{\mathrm{c}}$ & $2.1(1.4)$ & $\sim 17-22$ \\
\hline $\operatorname{Pd}(\mathrm{ac})_{2}$ & $\begin{array}{l}\mathrm{NaH}_{2} \mathrm{PO}_{2} \\
\text { THF : EtOH }=1: 19\end{array}$ & 59.3 & $1.8(1.1)$ & $\sim 22$ \\
\hline $\operatorname{Pd}(\mathrm{ac})_{2}$ & $\begin{array}{l}\mathrm{KBH}_{4}{ }^{\mathrm{d}} \\
\mathrm{THF}: \mathrm{EtOH}=1: 2.1\end{array}$ & 32.0 & $1.7(0.7)$ & $\sim 19$ \\
\hline
\end{tabular}

${ }^{\mathrm{a}}$ Hydrogenation conditions: $0.05 \mathrm{ml}$ cyclohexene, $0.09 \mathrm{wt} \%$ palladium, $10 \mathrm{ml}$ methanol, hydrogen pressure $10 \mathrm{psi}$, hydrogenation time 30 min. ${ }^{b}$ Estimated from TEM micrographs. ${ }^{\mathrm{c}}$ The use of $\mathrm{Pd}(\mathrm{acac})_{2}$ precursor with the $\mathrm{KBH}_{4}$ reduction at $60^{\circ} \mathrm{C}$ in THF: $\mathrm{EtOH}=1: 9$ results in $14.1 \%$ cyclohexane. This sample has not been investigated by TEM. ${ }^{d}$ Reduction performed immediately after mixing of the copolymer and precursor solutions; no previous stirring allowed.

tial embedding of the precursors and the resulting metal nanoparticles. At higher temperatures (reflux) during the preparation procedure a "softening" of the PS core might allow partial embedding to take place. However, there seems to be better incorporation of the precursors towards the micelle cores at lower or only somewhat elevated temperatures (below $T_{\mathrm{g}}$ ) with previous stirring for a certain amount of time. Thus, two trends can be observed: (i) lower catalytic activities for the reduction at reflux temperature in contrast to the room-temperature reductions by borohydride, due to the "softening" of the hydrophobic PS core (with more embedding) and (ii) lower catalytic activities at lower or only slightly elevated temperatures in combination with stirring, which allows a more complete diffusion of the precursor towards the core moiety.

Generally, the differences observed for the same precursor, for instance, $\operatorname{Pd}(\mathrm{ac})_{2}$, but prepared by different reduction conditions show that partial embedding is likely to be the determining factor for the catalytic properties of these systems. Less important is the simple influence of the precursor counterion.

Finally, another important feature can be seen from Table I. Spherical micelles and an increased catalytic activity are observed for the $\mathrm{NaH}_{2} \mathrm{PO}_{2}$ reduction (the reducing agent again added as an aqueous solution). For this reducing agent, the increased activity might additionally stem from its by-products. For example, $\mathrm{NaH}_{2} \mathrm{PO}_{2}$ as well as phosphinic or phosphorous acids are reported to be useful in hydrogen transfer catalysis in combination with palladium metal, and it is known that efficient catalytic hydrogenations at mild conditions are possible. ${ }^{35-37}$ Therefore, the use of this reducing agent could lead to promoting effects on the catalytic 


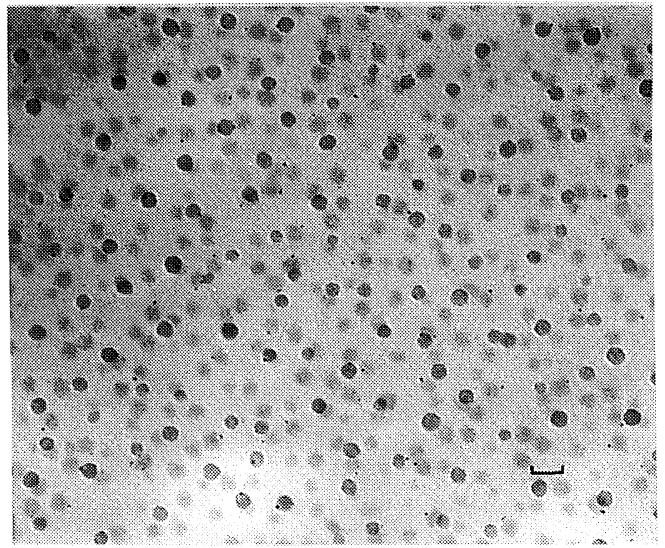

Figure 7. Palladium nanoparticles reduced by stirring the solution at room temperature from $\mathrm{Pd}(\mathrm{ac})_{2}$ precursor in the presence of $\mathrm{PS}-b$ PEO; solvent mixture THF : EtOH $=1: 19(\mathrm{v} / \mathrm{v})(\mathrm{bar}=42 \mathrm{~nm})$.

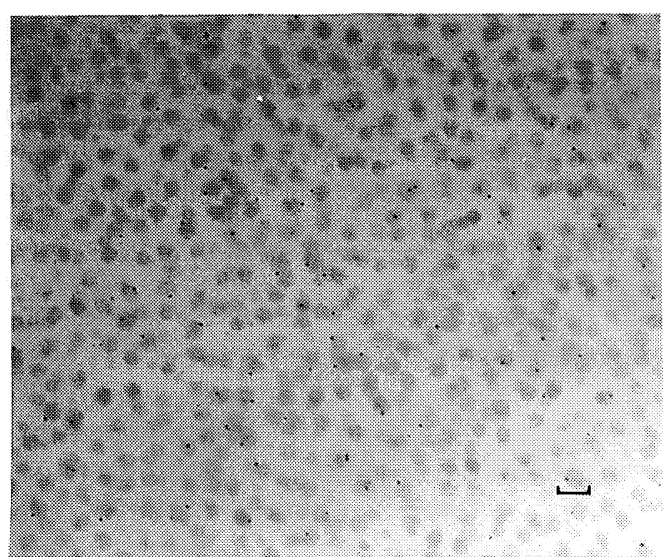

Figure 8. Palladium nanoparticles reduced by stirring the solution at room temperature from $\mathrm{Pd}(\mathrm{ac})_{2}$ precursor in the presence of PS- $b$ PEO; solvent mixture THF $: \mathrm{EtOH}=1: 2.1(\mathrm{v} / \mathrm{v})(\mathrm{bar}=53 \mathrm{~nm})$.

activity.

Table II lists the results obtained for palladium nanoparticles protected by PS- $b$-PEO. For this block copolymer two different solvent systems, based on THF : ethanol mixtures in different ratios, have been used in order to explore possible effects from swelling the micelle core.

As expected, the TEM micrographs indicate a trend for somewhat larger micelles (and therefore hydrophobic cores) for the solvent mixture with a higher THF content. A comparison of palladium nanoparticles reduced from $\mathrm{Pd}(\mathrm{ac})_{2}$ by stirring at room temperature in the presence of PS- $b$-PEO in the different solvent mixtures is shown in Figures 7 and 8; similar results for use of a reflux temperature are shown in Figure 9. The micrographs for the reduction at room temperature and at reflux temperature for the final solvent mixture THF : ethanol= $1: 2.1$ look similar, as do the catalytic activities. Again, it is interesting to note that for the $\mathrm{PdCl}_{2}$ precursor in combination with the $\mathrm{KBH}_{4}$ reduction, the micelle seems "larger" (with a trend to form "loose" aggregates) that it does for the reduction by refluxing. (This appears to be the case even though the solvent mixture is somewhat more polar due to the addition of the reducing agent in an aqueous solution). Figure 10 shows the palladium nanoparticles reduced from $\mathrm{PdCl}_{2}$ by $\mathrm{KBH}_{4}$

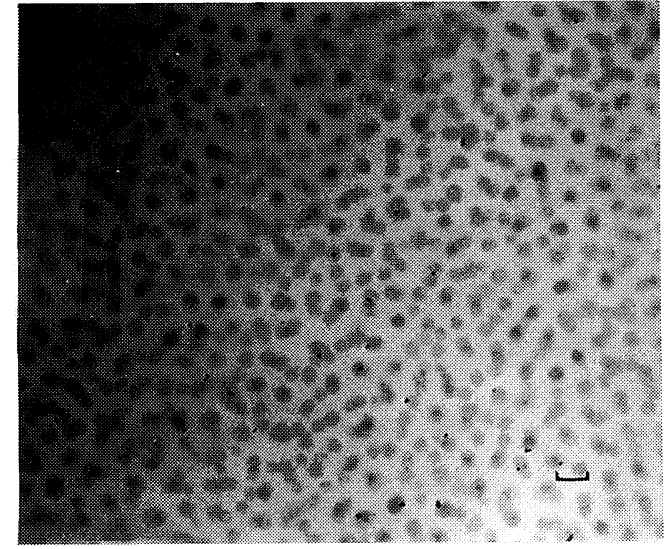

Figure 9. Palladium nanoparticles reduced by refluxing the solution from $\mathrm{Pd}(\mathrm{ac})_{2}$ precursor in the presence of PS- $b$-PEO; solvent mixture THF $:$ EtOH $=1: 2.1(\mathrm{v} / \mathrm{v})($ bar $=53 \mathrm{~nm})$.

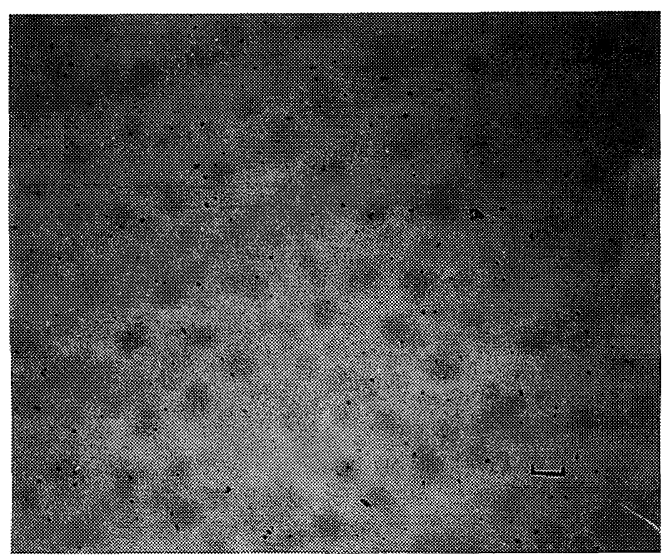

Figure 10. Palladium nanoparticles reduced by $\mathrm{KBH}_{4}$, from $\mathrm{PdCl}_{2}$ precursor in the presence of PS- $b$-PEO; solvent mixture THF : EtOH $=$ $1: 2.1($ bar $=42 \mathrm{~nm})$.

in the presence of PS- $b$-PEO and a final solvent mixture $\mathrm{THF}: \mathrm{EtOH}=1: 2.1$. However, as already mentioned with regard to the results in Table $I$, the influence of various ions present is crucial as well. ${ }^{30-34}$.

For the catalytic activities the general trend seems to be such that higher catalytic activities are found for the more polar solvent mixture containing smaller "more dense" micelle cores. In the case of the $\mathrm{PdCl}_{2}$ precursor reduced by $\mathrm{KBH}_{4}$ in THF : $\mathrm{EtOH}=1: 19$, a stringlike morphology is observed for the block copolymer, which obviously stems from the combined influence of the higher solvent polarity (and additional water) and the presence of the various ions. ${ }^{30-34}$ The TEM micrograph for this sample is shown in Figure 11. The increased catalytic activities in these cases seem to reflect the decreased degree of embedding of the palladium particles, due to the denser micelle cores present in the more polar solvent mixtures.

One exception seems to be the lowered value of the catalytic activity observed for the $\operatorname{Pd}(\mathrm{ac})_{2}$ precursor in the THF : $\mathrm{EtOH}=1: 19(\mathrm{v} / \mathrm{v})$ solvent mixture. However, an elevated temperature $\left(60^{\circ} \mathrm{C}\right)$ was used during the reduction which could cause the "softening" of the micelle core to some extent (thus enabling partial embedding of the palladium nanoparticles). Indeed some micelle diameters found on the TEM micrograph are 


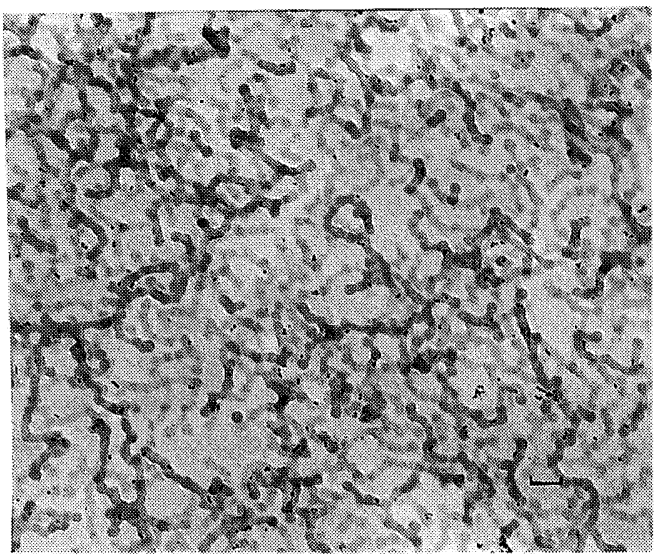

Figure 11. Palladium nanoparticles reduced by $\mathrm{KBH}_{4}$ from $\mathrm{PdCl}_{2}$ precursor in the presence of PS- $b$-PEO; solvent mixture THF $: \mathrm{EtOH}=$ $1: 19($ bar $=62 \mathrm{~nm})$.

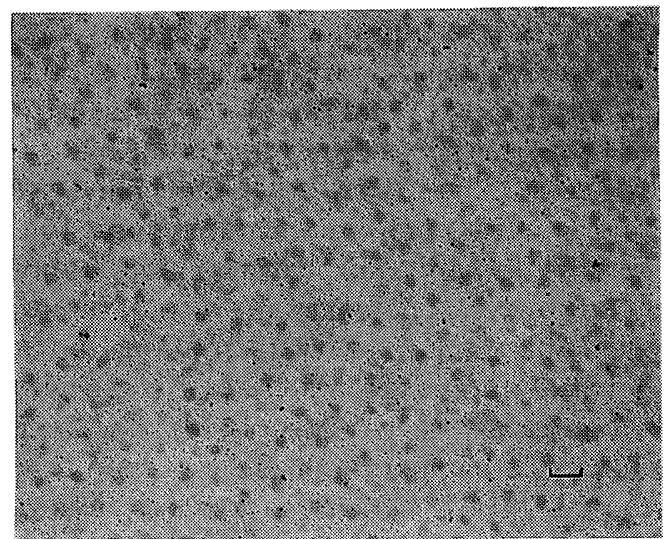

Figure 12. Palladium nanoparticles reduced by $\mathrm{KBH}_{4}$ from $\mathrm{Pd}(\mathrm{ac})_{2}$ precursor in the presence of PS- $b$-PEO; solvent mixture THF : EtOH $=$ $1: 2.1$, no stirring time allowed $($ bar $=53 \mathrm{~nm})$.

significantly larger than those from the similar roomtemperature reduction.

One additional experiment was very relevant to the question of whether the diffusion of the metal precursor towards the micelle core was crucial for the catalytic properties. It involved reduction of $\mathrm{Pd}(\mathrm{ac})_{2}$ in the solvent mixture possessing the higher THF content (both chosen aspects usually resulting in increased embedding). However, a fast reduction method $\left(\mathrm{KBH}_{4}\right)$ was employed immediately after mixing of the copolymer and the precursor solutions (therefore preventing extensive diffusion). The fast reduction method was selected to ensure reduction of the precursor before its diffusion towards the micelle core. A higher catalytic activity was found for this sample. The TEM micrograph shown in Figure 12 reveals an interesting picture, namely that the palladium particles are found to surround the micelle core but are obviously not embedded in it. A similar feature was also observed for $\mathrm{Pd}(\mathrm{acac})_{2}$ as a precursor; however, in this case, the particles coexisted with some large agglomerates. The pertinent TEM micrograph is shown in Figure 13. This preparation still needs to be optimized, followed by evaluation of its catalytic activity. Such metal-block copolymer morphologies with small metal nanoparticles surrounding the micelle cores are certainly very interesting. They could be important not

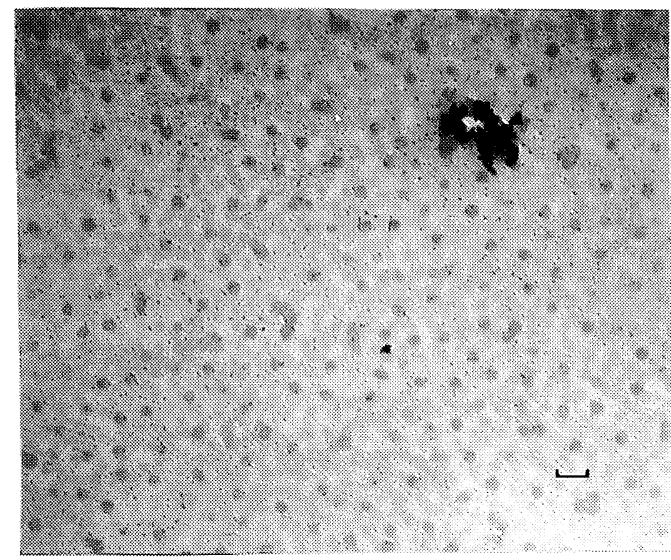

Figure 13. Palladium nanoparticles reduced by $\mathrm{KBH}_{4}$, from $\mathrm{Pd}(\mathrm{acac})_{2}$ precursor in the presence of PS- $b$-PEO; solvent mixture $\mathrm{THF}: \mathrm{EtOH}=1: 19($ bar $=53 \mathrm{~nm})$.

Table III. Platinum nanocatalysts protected by PS- $b$-PEO and PS- $b$-PMAA

\begin{tabular}{|c|c|c|c|c|}
\hline Precursor & $\begin{array}{l}\text { Reduction } \\
\text { method }\end{array}$ & $\begin{array}{l}\text { Catalytic } \\
\text { activity }\end{array}$ & $\begin{array}{c}\text { Average } \\
\text { particle } \\
\text { diameter } / \mathrm{nm}\end{array}$ & $\begin{array}{c}\text { Micelle } \\
\text { diameter }^{b}\end{array}$ \\
\hline \multicolumn{2}{|c|}{ Copolymer } & $\begin{array}{l}\% \text { cyclo- } \\
\text { hexane }^{a}\end{array}$ & (std. dev.) & $\mathrm{nm}$ \\
\hline \multicolumn{5}{|c|}{ PS- $b$-PEO } \\
\hline \multicolumn{5}{|c|}{ PS- $b$-PEO } \\
\hline $\begin{array}{r}\mathrm{H}_{2} \mathrm{PtCl}_{6} \\
\text { PS }\end{array}$ & \multicolumn{4}{|c|}{ PS- $b$-PMAA } \\
\hline $\begin{array}{r}\mathrm{H}_{2} \mathrm{PtCl}_{6} \\
\mathrm{PS}\end{array}$ & $\begin{array}{l}\mathrm{KBH}_{4}{ }^{\mathrm{d}} \\
\text { PMAA }\end{array}$ & 63.0 & $3.3(0.9)$ & $\sim 15$ \\
\hline $\begin{array}{r}\mathrm{Pt}(\mathrm{acac})_{2} \\
\mathrm{PS}\end{array}$ & $\begin{array}{l}\text { Refluxing } \\
\text { PMAA }\end{array}$ & 60.7 & $2.8(1.0)$ & $\sim 15-20$ \\
\hline
\end{tabular}

a Hydrogenation conditions: $0.05 \mathrm{ml}$ cyclohexene, $0.16 \mathrm{wt} \%$ platinum, $10 \mathrm{ml}$ methanol, hydrogen pressure $10 \mathrm{psi}$, hydrogenation time $30 \mathrm{~min} .{ }^{\mathrm{b}}$ Estimated from TEM micrographs. ${ }^{\mathrm{c}}$ Initial solvent mixture, tetrahydrofuran : ethanol $=1: 2.1 \quad(\mathrm{v} / \mathrm{v})$. ${ }^{\mathrm{d}}$ Initial solvent, ethanol. ${ }^{\mathrm{c}}$ Initial solvent, ethanol: water $=10: 3$; reflux time, 3 days (oil-bath temperature $100^{\circ} \mathrm{C}$ ).

only for catalytic applications, but could as well be the starting point for the development of, for example, conductive, low-density materials as well. Of course, a different (conductive) type of corona would have to be developed, or a conductive polymer would have to be included as an additional blend component.

Finally, as already mentioned in the discussion of the results in Table $\mathrm{I}$, reduction by $\mathrm{NaH}_{2} \mathrm{PO}_{2}$ results in an increased catalytic activity also for the PS- $b$-PEO block copolymer, probably due to promoting effects from the hypophosphite salt. ${ }^{35-37}$

Some experiments for platinum nanoparticles have been performed as well, and the respective results are listed in Table III. TEM micrographs for platinum nanoparticles reduced by $\mathrm{KBH}_{4}$ from $\mathrm{H}_{2} \mathrm{PtCl}_{6}$ precursor in the presence of PS- $b$-PMAA and PS- $b$-PEO are shown in Figures 14 and 15, respectively. Interestingly, the catalytic activities observed for the same reduction methods but with the two different block copolymers employed are very similar. This seems to imply that the types and lengths of the hydrophilic corona blocks have only a very limited influence in this case. Since the 


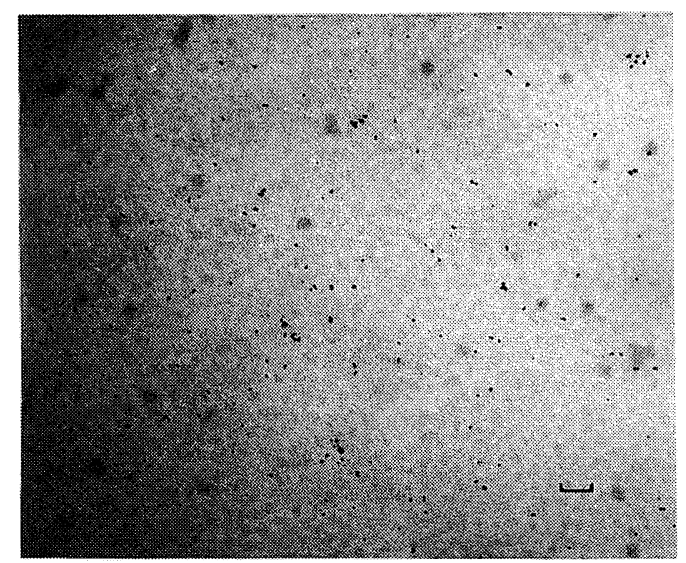

Figure 14. Platinum nanoparticles reduced by $\mathrm{KBH}_{4}$, from $\mathrm{H}_{2} \mathrm{PtCl}_{6}$ precursor in the presence of PS- $b$-PMAA (bar $=42 \mathrm{~nm})$.

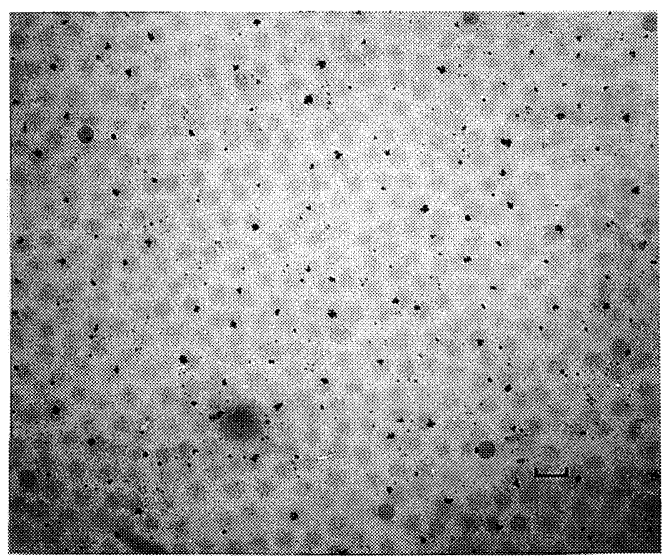

Figure 15. Platinum nanoparticles reduced by $\mathrm{KBH}_{4}$, from $\mathrm{H}_{2} \mathrm{PtCl}_{6}$ precursor in the presence of PS- $b$-PEO; solvent mixture THF : EtOH $=$ $1: 2.1($ bar $=42 \mathrm{~nm})$.

precursor was $\mathrm{H}_{2} \mathrm{PtCl}_{6}$ (which possesses only small hydrophobicity), only a limited incorporation into the hydrophobic micelle cores could be expected. Therefore, for this sample the differences in block lengths of the hydrophobic blocks should not be as influential, and this is confirmed by the catalytic results presented.

In contrast to the results obtained for the palladium samples, reduction with $\mathrm{KBH}_{4}$ results in lower catalytic activities when compared to the reduction by refluxing. The influence of reduction by-products might have an influence in this case.

The activity in the case of reduction by refluxing is lowered, however, if $\mathrm{Pt}(\mathrm{acac})_{2}$ is used as the precursor. In this case the higher hydrophobicity and associated partial embedding might be responsible. Comparison with reduction of $\mathrm{Pt}(\mathrm{acac})_{2}$ with $\mathrm{KBH}_{4}$ however, could not be carried out definitively under the present conditions.

\section{CONCLUSIONS}

Amphiphilic block copolymers are highly interesting and versatile components for polymer-metal systems, due to the variety of options they offer for tuning and controlling such systems for various specific applications. For instance, certain desired catalytic properties, such as catalyst activities, can be easily varied. In fact, the results obtained in the present study show that a variety of factors can be used to influence such catalytic properties. Crucial factors appear to be the choice of the metal precursor (based, for example, on hydrophobic or steric criteria), reduction method and conditions (including temperature and solvent), as well as block copolymer morphologies.

Such block copolymer-metal systems might even offer the possibility of altering and/or controlling catalytic properties during the course of a reaction. This might be achieved, for instance, by simply inducing a morphological change (by the change of, e.g., solvent composition or temperature). Furthermore, certain metal-block copolymer morphologies in combination with suitable (conductive) block copolymer or blend components could be very promising for many other technological applications, such as conductive, low-density films and composite materials.

Another important aspect that can contribute significantly to the versatility of such block copolymermetal systems is the ratio of the amounts of the two blocks, and the investigation of its influence on the catalytic properties should be very promising.

Hydrophobic block types other than polystyrene are of further interest and are recommended for future investigations. In addition to various block copolymers, certain graft or comb polymers are also of interest since they might offer similarly versatile options for tailoring metal-polymer composite materials. This class of polymers (consisting of a hydrophobic backbone, and hydrophilic side chains) might be especially useful for incorporating metal particles in a purely hydrophobic environment within a polar solvent system.

Acknowledgments. We would like to thank Professor A. R. Pinhas, Department of Chemistry, University of Cincinnati, for his help in analyzing the reaction mixtures by gas chromatography. We would also like to acknowledge the financial support provided by the National Science Foundation through Grant DMR9422223 (Polymers Program, Division of Materials Research).

\section{REFERENCES}

1. H. Hirai and N. Toshima, in "Catalysis by Metal Complexes, Tailored Metal Catalysts," Y. Iwasawa, Ed., D. Reidel Publishing Company, Dordrecht, 1986.

2. J. S. Bradley, in "Clusters and Colloids. From Theory to Applications," G. Schmid, Ed., VCH, Weinheim, 1994.

3. H. Hirai, Y. Nakao, and N. Toshima, J. Macromol. Sci., Chem., A13, 727 (1979).

4. H. Hirai, H. Chawanya, and N. Toshima, Makromol. Chem., Rapid Commun., 2, 99 (1981).

5. H. Hirai, H. Chawanya, and N. Toshima, Reactive Polymers, 3, 127 (1985).

6. a) N. Toshima, T. Yonezawa, and K. Kushihashi, J. Chem. Soc., Faraday Trans., 89, 2537 (1993). b) T. Yonezawa and N. Toshima, J. Chem. Soc., Faraday Trans., 91, 4111 (1995).

7. M. Antonietti, E. Wenz, L. Bronstein, and M. Seregina, $A d v$. Mater., 7, 1000 (1995).

8. M. Antonietti, S. Förster, J. Hartmann, and S. Oestreich, Macromolecules, 29, 3800 (1996).

9. M. Moffitt and A. Eisenberg, Chem. Mater., 7, 1178 (1995)

10. M. Moffitt, L. McMahon, V. Pessel, and A. Eisenberg, Chem. Mater., 7, 1185 (1995). 
11. M. Moffitt, K. Khougaz, and A. Eisenberg, Acc. Chem. Res., 29, 95 (1996).

12. J. P. Spatz, A. Roescher, and M. Möller, Polym. Prepr., 37, 409 (1996).

13. J. P. Spatz, A. Roescher, and M. Möller, Adv. Mater., 8, 337 (1996).

14. C. C. Cummins, R. R. Schrock, and R. E. Cohen, Chem. Mater., 4, 27 (1992)

15. Y. N. C. Chan, G. S. W. Craig, R. R. Schrock, and R. E. Cohen, Chem. Mater., 4, 885 (1992).

16. R. T. Clay and R. E. Cohen, Supramol. Sci., 2, 183 (1995).

17. B. H. Sohn and R. E. Cohen, Acta Polymerica, 47, 340 (1996).

18. R. T. Clay and R. E. Cohen, Supramol. Sci., 4, 113 (1997).

19. R. T. Clay and R. E. Cohen, Supramol. Sci., (1998), in press.

20. A. Henglein, Chem. Rev., 89, 1861 (1989).

21. H. Bönnemann, W. Brijoux, and T. Joussen, Angew. Chem. Int. Ed. Engl., 29, 273 (1990).

22. H. Bönnemann, W. Brijoux, R. Brinkmann, R. Fretzen, T. Joussen, R. Köppler, B. Korall, P. Neiteler, and J. Richter, $J$. Mol. Cat., 86, 129 (1994).

23. a) A. B. R. Mayer and J. E. Mark, PMSE Preprints, 73, 220 (1995). b) A. B. R. Mayer and J. E. Mark, in "Nanotechnology, Molecularly Designed Materials," G.-M. Chow and K. E. Gonsalves, Ed., ACS Symposium Series 622, American Chemical Society, Washington, 1996, pp 137-150. c) A. B. R. Mayer and J. E. Mark, Polym. Bull., 37, 683 (1996). d) A. B. R. Mayer and
J. E. Mark, Macromol. Rept, A33, 451 (1996).

24. a) A. B. R. Mayer and J. E. Mark, Polym. Prepr., 37, 459 (1996). b) A. B. R. Mayer and J. E. Mark, J. Coll. Polym. Sci., 275, 333 (1997).

25. A. B. R. Mayer and J. E. Mark, J. Polym. Sci., A: Polym. Chem., 35, 3151 (1997).

26. A. B. R. Mayer and J. E. Mark, J. Polym. Sci., B: Polym. Phys., 35, 1207 (1997)

27. A. B. R. Mayer and J. E. Mark, Europ. Polym. J., 34, 103 (1998).

28. C.-W. Chen and M. Akashi, J. Polym. Sci., A: Polym. Chem., 35, 1329 (1997).

29. D. H. Napper, in "Polymeric Stabilization of Colloidal Dispersions," Academic Press, London, 1983.

30. L. Zhang and A. Eisenberg, Science, 272, 1777 (1996).

31. Z. Gao, S. K. Varshney, S. Wong, and A. Eisenberg, Macromolecules, 27, 7923 (1994).

32. L. Zhang and A. Eisenberg, Science, 268, 1728 (1995).

33. L. Zhang and A. Eisenberg, Macromolecules, 29, 8805 (1996).

34. K. Yu and A. Eisenberg, Macromolecules, 29, 6359 (1996).

35. R. Sala, G. Doria, and C. Passarotti, Tetrahedron Lett., 25, 4565 (1984).

36. S. K. Boyer, J. Bach, J. McKenna, and E. Jagdmann, Jr., J. Org. Chem., 50, 3408 (1985).

37. I. D. Entwistle, A. E. Jackson, R. A. W. Johnstone, and R. P. Telford, J. Chem. Soc., Perkin Trans. 1, 443 (1977). 